\title{
Correction to: High Depression Symptoms and Burnout Levels Among Parents of Children with Autism Spectrum Disorders: A Multi-Center, Cross-Sectional, Case-Control Study
}

\author{
Meryem Özlem Kütük ${ }^{1}$ - Ali Evren Tufan ${ }^{2}(1) \cdot$ Fethiye Kılıçaslan $^{3}$ - Gülen Güler ${ }^{4}$. Fatma Çelik ${ }^{5}$. Ebru Altıntaş ${ }^{6}$. \\ Cem Gökçen ${ }^{7}$. Mehmet Karadağ ${ }^{7} \cdot$ Çiğdem Yektaş $^{8} \cdot$ Tuba Mutluer $^{9} \cdot$ Hasan Kandemir $^{10}$ • Ahmet Büber ${ }^{11}$. \\ Zehra Topal $^{7}$. Ufuk Acikbas ${ }^{12}$ • Aslı Giray ${ }^{13}$. Özgür Kütük ${ }^{14}$
}

Published online: 16 February 2021

(c) Springer Science+Business Media, LLC, part of Springer Nature 2021

\section{Correction to: Journal of Autism and Developmental Disorders https://doi.org/10.1007/s10803-021-04874-4}

The original version of the article has unfortunately missed the revised affiliations for the following authors.

The corrected affiliations are given below:

Dr. Ufuk Acikbas - Department of Health and Life Sciences, Oxford Brookes University, Oxford, United Kingdom

Dr. Çiğdem Yektaş - Uskudar University Medical Faculty, Department of Child and Adolescent Psychiatry

The original article has been corrected.

The original article can be found online at https://doi.org/10.1007/ s10803-021-04874-4.

\section{Ali Evren Tufan}

tevrenus@yahoo.com

1 Department of Child and Adolescent Psychiatry, Baskent University, Dr. Turgut Noyan Medical and Research Center, Adana, Turkey

2 Department of Child and Adolescent Psychiatry, Bolu Abant İzzet Baysal University Medical Faculty, Bolu, Turkey

3 Department of Child and Adolescent Psychiatry, Mehmet Akif İnan Education and Research Hospital, Şanlıurfa, Turkey

4 Department of Child and Adolescent Psychiatry, Mersin University, Mersin, Turkey

5 Department of Child and Adolescent Psychiatry, Malatya State Hospital, Malatya, Turkey

6 Department of Psychiatry, Başkent University, Dr. Turgut Noyan Medical and Research Center, Adana, Turkey

7 Department of Child and Adolescent Psychiatry, Gaziantep University, Gaziantep, Turkey
Publisher's Note Springer Nature remains neutral with regard to jurisdictional claims in published maps and institutional affiliations.
8 Uskudar University Medical Faculty, Department of Child and Adolescent Psychiatry, Istanbul, Turkey

9 Department of Child and Adolescent Psychiatry, Koç University, İstanbul, Turkey

10 Department of Child and Adolescent Psychiatry, Celal Bayar University, Manisa, Turkey

11 Department of Child and Adolescent Psychiatry, Pamukkale University, Denizli, Turkey

12 Department of Health and Life Sciences, Oxford Brookes University, Oxford, United Kingdom

13 Department of Genetics and Bioengineering, Alaaddin Keykubat University, Antalya, Turkey

14 Department of Medical Genetics, Başkent University, Adana Dr. Turgut Noyan Medical and Research Center, Adana, Turkey 